\title{
Morbidity and predictors of delayed recognition of iatrogenic ureteric injuries
}

\author{
Jennifer A. Locke, MD; Sarah Neu, MD; Sender Herschorn, MD \\ University of Toronto, Sunnybrook Health Sciences Centre, Toronto, ON, Canada
}

Cite as: Locke JA, Neu S, Herschorn S. Morbidity and predictors of delayed recognition of iatrogenic ureteric injuries. Can Urol Assoc J 2022;16(1):El-6. http://dx.doi.org/10.5489/cuaj.7271

Published online August 26, 2021

\section{Abstract}

Introduction: Although intraoperative iatrogenic ureteric injuries (IUI) are rare, significant consequences can occur if they are unrecognized at the time. The focus of our study is to characterize the associated morbidity and identify predictors of delayed recognition of IUI.

Methods: Sunnybrook Health Sciences Centre Research Ethics Board approved the study. Patients with a diagnosis of IUI between 2002 and 2020 were identified through an institutional electronic medical record system. Data pertaining to the demographic characteristics, diagnosis, and management of IUI, as well as overall outcomes were collected retrospectively.

Results: Of the 103 patients identified, 83\% were female, 52\% had previous abdominal surgery, and $18 \%$ had previous radiation. The median age was 67 (range 21-88) years. Twenty percent were not recognized at the time of surgery. Although delayed recognition was not a significant predictor for poor outcome after subsequent repair (i.e., hydronephrosis, ureteric stricture/obstruction), it was associated with substantial morbidity to the patient (i.e., additional procedures) and increased cost to the healthcare system (i.e., longer hospital stay, re-admission to hospital). Patients who underwent laparoscopic surgery had an 11 times more likely chance of having an unrecognized IUI as compared to those who underwent open surgery (odds ratio 11.515, $\mathrm{p}=0.0001$ ).

Conclusions: Delayed recognition of IUI may be associated with considerable adverse effects. In this retrospective case series, we identified laparoscopic surgery as a significant predictor for delayed recognition of IUI. This information underscores the need for future studies to facilitate intraoperative identification of ureteric injuries, particularly during laparoscopic procedures.

\section{Introduction}

Although iatrogenic ureteric injuries (IUI) are rare, with an incidence of $0.5-10 \%,{ }^{1}$ intraoperatively unrecognized IUI can have significant consequences. ${ }^{2}$ In a population-based study of 1753 hysterectomy-associated IUI, the IUI that went unrecognized at the time of injury had higher rates of 90-day re-admission (67\% vs. 13\%), sepsis (odds ratio [OR] 2.0, 95\% confidence interval [Cl] 1.2-3.5; and 11.9, 95\% Cl 9.9-14.3), urinary fistula (OR 5.9, 95\% Cl 2.2-16, and 124, 95\% Cl 95.7-16), acute renal insufficiency (OR 23.8, 95\% Cl 20.1-28.2), and death (OR 1.4, 95\% Cl 1.03-1.9, $\mathrm{p}=0032)$ as compared to those recognized at the time of injury. ${ }^{3}$ In a study by Hove et al evaluating insurance claims in a Danish database, the authors noted that the majority of claims $(88 \%)$ were associated with delayed recognition of IUI and that presentations included flank pain, febrile postoperative course, ileus, urinary leakage, and a transient rise in serum creatinine. ${ }^{4}$ Unrecognized IUI can have substantial consequences for the patient, increased costs for the healthcare system, and may result in litigation. Therefore, intraoperative recognition of IUI is important.

Surgical techniques to repair IUI include uretero-neocystotomy, uretero-ureterostomy, suture repair, ureteric stent placement, and nephrostomy tube placement. ${ }^{1,5-7}$ Various case series (maximum 164 patients) have evaluated the outcomes of IUI repair and found very high success rates if recognized at the time of injury, regardless of technique..$^{8-14}$ However, the management of IUIs recognized after a delay has not been as well-studied. In a retrospective study of IUIs after delayed recognition, $11 / 21$ (52.5\%) had successful ureteral stenting but only $3 / 11$ (27.3\%) had resolution requiring no further intervention. ${ }^{15}$ The outcome of reconstructive surgery was not mentioned. ${ }^{15}$ In a case series of 82 IUIs, AI-Awadi et al found that when an IUI was recognized and repaired within one week of the initial surgery, where the type of repair was not specified, mean hospital stay was shorter (4.8 vs. 10.1 days) and there were fewer complications compared to those repaired after one week. ${ }^{16}$

The aims of our study are to characterize the associated morbidity and outcomes, as well as identify predictors of delayed recognition of IUI. 


\section{Methods}

Sunnybrook Health Sciences Centre Research Ethics Board approved the study. Patients with a diagnosis of IUI between 2002 and 2020 were identified through an institutional electronic medical record system. Collected data in this retrospective chart review included demographic variables (age, gender, and comorbidities), previous radiation/abdominal surgery, initial diagnosis and surgery, time of diagnosis (immediate or delayed), type of surgery (laparoscopic or open), location of IUI (distal, middle, or upper ureter), and type of repair (uretero-neocystotomy, uretero-ureterostomy, suture repair, stent only, or no treatment). The outcomes evaluated included presence of new or worsening hydronephrosis on followup imaging (ultrasound or computed tomography [CT] scan), presence of stricture (defined as hydronephrosis proximally to a narrowing of the ureter at the site of previous repair on followup imaging), and most importantly, the presence of ureteric obstruction (defined as presence of hydronephrosis proximally and narrowing of the ureter at the site of previous repair with reflux not being the etiology of the hydronephrosis).

Logistic regression analysis was used to determine if there was any significant relationship between demographic variables, patient, and operative factors (previous radiation, previous surgery, initial diagnosis, initial procedure type) and delayed presentation of IUI. Logistic regression analysis was also used to determine if there was any significant relationship between delayed recognition of IUI and outcomes (hydronephrosis, ureteric stricture, and ureteric obstruction). Statistical significance was defined as $p<0.05$. Data analysis was done with IBM ${ }^{\circledR}$ SPSS software.

\section{Results}

\section{Demographics}

Between 2002 and 2020, 103 patients with IUI were identified at our institution. The average age of the patients was 58 (standard deviation [SD] 14) and range of ages was 21-88 (median 67). Eighty-three percent of the patients were female. Evaluating comorbidities, we found $57 \%$ had previous surgery, $31 \%$ had hypertension (HTN), and $11 \%$ had diabetes (DM). Fifty-two percent had previous abdominal surgery and $18 \%$ had previous radiation (Table 1 ).

Eighty percent of the injuries were recognized at time of the initial surgery. The remainder had delayed recognition (defined as repair not on same day as initial surgery) (Table 1). Of the 21 patients who had delayed recognition of IUI, median time to presentation was seven days (range 1-270). Eight of 21 presented to hospitals other than our institution. Presenting symptoms included nausea/vomiting, fever, and flank pain,

\begin{tabular}{|c|c|}
\hline Comorbidities & Patient cohort $n=103(\%)$ \\
\hline Parkinson's & $1(1.0)$ \\
\hline Hypertension (HTN) & $32(31.1)$ \\
\hline Diabetes (DM) & $11(10.7)$ \\
\hline $\begin{array}{l}\text { High body mass index } \\
\text { (BMI) }\end{array}$ & $3(2.9)$ \\
\hline Liver disease & $1(1.0)$ \\
\hline $\begin{array}{l}\text { Coronary artery disease } \\
\text { (CAD) }\end{array}$ & $7(6.8)$ \\
\hline Previous surgery (any) & $59(57.3)$ \\
\hline \multicolumn{2}{|c|}{ Patient and operative factors } \\
\hline \multicolumn{2}{|c|}{ Previous abdominal surgery } \\
\hline Yes & $54(52.4)$ \\
\hline No & $35(34.0)$ \\
\hline Unknown & $14(13.6)$ \\
\hline \multicolumn{2}{|l|}{ Previous radiation } \\
\hline Yes & $18(17.5)$ \\
\hline No & 85 (82.5) \\
\hline \multicolumn{2}{|l|}{ Type of surgery } \\
\hline Laparoscopic & $16(15.5)$ \\
\hline Open & $87(84.5)$ \\
\hline \multicolumn{2}{|c|}{ Timing of injury recognition } \\
\hline Immediate & $82(79.6)$ \\
\hline Delayed & $21(20.3)$ \\
\hline \multicolumn{2}{|l|}{ Location of injury } \\
\hline Distal & $67(65.0)$ \\
\hline Mid & $34(33.0)$ \\
\hline Proximal & $2(1.9)$ \\
\hline \multicolumn{2}{|l|}{ Initial procedure type } \\
\hline $\begin{array}{l}\text { Total abdominal } \\
\text { hysterectomy }\end{array}$ & $57(55.3)$ \\
\hline Cystectomy* & $3(2.9)$ \\
\hline Bowel resection & $32(31.1)$ \\
\hline Pelvic exenteration* & $2(1.9)$ \\
\hline $\begin{array}{l}\text { Endoscopic ureteral } \\
\text { surgery }\end{array}$ & $1(1.0)$ \\
\hline Vascular surgery & $4(3.9)$ \\
\hline Other & $4(3.9)$ \\
\hline
\end{tabular}

\begin{tabular}{lccc}
\hline Repair type & All & $\begin{array}{c}\text { Recognized } \\
(\mathbf{8 2})\end{array}$ & $\begin{array}{c}\text { Unrecognized } \\
(\mathbf{2 1 )}\end{array}$ \\
\hline $\begin{array}{l}\text { Uretero-neocystotomy } \pm \\
\text { psoas hitch } \pm \text { boari flap }\end{array}$ & $54(52.4 \%)$ & $37(45.1 \%)$ & $17(81.0 \%)$ \\
Uretero-ureterostomy & $30(29.1 \%)$ & $28(34.1 \%)$ & $2(9.5 \%)$ \\
Suture repair & $14(13.6 \%)$ & $14(17.1 \%)$ & 0 \\
Stent only & $3(2.9 \%)$ & $2(2.4 \%)$ & $1(4.8 \%)$ \\
No treatment & $1(1.0 \%)$ & $1(1.2 \%)$ & 0 \\
Nephrostomy drainage & $1(1.0 \%)$ & 0 & $1(4.8 \%)$ \\
\hline
\end{tabular}

*These procedures traditionally involve transection of the ureter at time of bladder removal. Therefore, in this series, iatrogenic ureteric injuries were defined as unexpected injury to the ureter aside from the preoperatively planned transection of the ureter.

while presenting signs included ileus, incisional infection, increased drain output, sepsis, hydronephrosis, urinary incon- 


\begin{tabular}{lc}
\hline \multicolumn{2}{l}{$\begin{array}{l}\text { Table 2. Presentations and morbidity associated with } \\
\text { delayed recognition of IUI (n=21) }\end{array}$} \\
\hline Presentation & $\mathbf{n}(\%)$ \\
\hline Symptoms & \\
Nausea/vomiting & $4(19.0)$ \\
Fever & $7(33.3)$ \\
Flank pain & $4(19.0)$ \\
Signs & \\
Ileus & $3(14.2)$ \\
Incisional infection & $1(4.8)$ \\
Increased drain output & $4(19.0)$ \\
Sepsis & $7(33.3)$ \\
Hydronephrosis & $5(23.4)$ \\
Urinary incontinence/urine per vagina & $4(19.0)$ \\
or rectum & $1(4.8)$ \\
Recurrent urinary tract infection & $3(14.2)$ \\
Unknown symptoms and signs & \\
Morbidity & $15(71.4)$ \\
Nephrostomy tube (NT) & $3(14.2)$ \\
Ureteric stent & 7 days (1-9) \\
Time to first intervention, median & $10(47.6)$ \\
(range) & \\
Multiple procedures (i.e., NT, ureteric & \\
stent, nephrostogram, retrograde & \\
pyelogram) & Immediate \\
Hospitalization time (mean \pm standard \\
deviation)
\end{tabular}

tinence/leakage per vagina or rectum, and recurrent urinary tract infections (Table 2).

\section{Overall outcomes}

For IUI location, $65 \%$ were distal, 33\% were mid, and $2 \%$ were upper ureter (Table 1 ). The majority were repaired by uretero-neocystotomy \pm psoas hitch \pm boari flap $(52 \%)$, followed by uretero-ureterostomy (29\%), suture repair (14\%), stent only $(3 \%)$, nephrostomy tube drainage $(1 \%)$, and no treatment (1\%; patient was palliative). Of the 103 patients in the study, 10 (10\%) developed new or worsening hydronephrosis, five $(5 \%)$ had ureteric stricture, and four $(4 \%)$ had ureteric obstruction after repair of IUI. There were no statistical differences in hydronephrosis, ureteric stricture, and ureteric obstruction based on repair type or any other variables recorded in the study.

\section{Predictors for delayed recognition of IUI}

Univariate logistic regressions were performed to ascertain the effects of previous radiation, previous surgery, initial diagnosis, type of surgery, and initial procedure type individually on the likelihood that patients had a delayed pre- sentation of IUI. The logistic regression model for type of surgery (laparoscopic vs. open) was statistically significant $(p<0.005)$. The model explained $24 \%$ (Nagelkerke $R^{2}$ ) of the variance in time of diagnosis and correctly classified $84 \%$ of cases. Patients who underwent laparoscopic surgery had an 11 times more likely chance of delayed presentation of IUI as compared to patients who underwent open surgery (OR 11.515, $\mathrm{p}=0.0001$ ). No other factors evaluated were associated with a delayed presentation of IUI (Table 3).

\section{Delayed recognition of IUI and outcomes}

In the 21 patients whose IUI was discovered after a delay, there were no statistically significant differences in hydronephrosis, ureteric stricture, and ureteric obstruction after treatment compared with those recognized immediately (Table 3 ), regardless of repair type (uretero-neocystotomy \pm psoas hitch \pm boari flap [81\%], uretero-ureterostomy [9\%], stent only [5\%], or nephrostomy tube drainage [5\%]) (Table 1).

\section{Delayed recognition of IUI and morbidity}

In addition to requiring an operation to repair the IUI, most patients with delayed recognition of IUI experienced significant morbidity. Fifteen required nephrostomy tube and three required ureteric stent, with a median time to first intervention of seven days (range 1-9). Approximately half went on to have multiple interventions (i.e., nephrostomy tube changes, ureteric stent changes) prior to definitive repair of the IUI. Average hospitalization time was longer in the delayed recognition group ( $21 \pm 40$ days vs. $12 \pm 10$ days in the immediate treatment group, $p=0.0001$ ) and $6 / 21$ patients required re-admission to hospital for symptoms related to the delayed diagnosis of IUI, imposing a cost burden to the healthcare system. Lastly, one patient had persistent wound drainage for three months following his/her initial surgery before the IUI was recognized, and another patient had ureteric stent changes for over 10 years to manage the non-healing IUI before being referred for definitive repair.

\section{Discussion}

One of the objectives of this retrospective study was to identify predictors for delayed recognition of IUI. Previous radiation, previous surgery, initial diagnosis, type of surgery, initial procedure type, and demographics were not found to be predictors. We did find that laparoscopic surgery had a higher likelihood of delayed presentation of IUI than open surgery (OR 11.515, $\mathrm{p}=0.000$ ). The other objective of this retrospective study was to characterize associated morbidity with delayed presentation of IUI. We found that delayed recognition of IUI was associated with substantial patient morbidity, in addition to requiring another operation to repair the IUI. 


\begin{tabular}{|c|c|c|c|c|c|}
\hline Predictor & B & Standard error & Odds ratio & $95 \% \mathrm{Cl}$ & $\mathbf{p}$ \\
\hline \multicolumn{6}{|l|}{ Previous radiation } \\
\hline \multicolumn{6}{|l|}{ Yes (ref) } \\
\hline No & 0.134 & 0.628 & 1.143 & $0.333-3.917$ & 0.832 \\
\hline \multicolumn{6}{|l|}{ Previous surgery } \\
\hline \multicolumn{6}{|l|}{ Unknown (ref) } \\
\hline Yes & -0.249 & .722 & 0.779 & 0.189-3.205 & 0.73 \\
\hline No & 0.748 & 0.841 & 2.114 & 0.407-10.977 & 0.373 \\
\hline \multicolumn{6}{|l|}{ Initial diagnosis } \\
\hline \multicolumn{6}{|l|}{ Other (ref) } \\
\hline $\begin{array}{l}\text { Endometrial/uterine cancer/cervical cancer/ovarian/adnexal sarcoma/ } \\
\text { benign gynecology }\end{array}$ & 0.021 & 1.164 & 1.021 & 0.104-9.985 & 0.986 \\
\hline Colorectal cancer/ diverticular disease/benign general surgery & -0.043 & 1.208 & 0.958 & $0.09-10.235$ & 0.972 \\
\hline Vascular & 0.223 & 1.565 & 1.25 & $0.058-26.869$ & 0.887 \\
\hline Urological cancer/benign urology & -1.386 & 1.803 & 0.25 & $0.007-8.56$ & 0.442 \\
\hline \multicolumn{6}{|l|}{ Type of surgery } \\
\hline \multicolumn{6}{|l|}{ Open (ref) } \\
\hline Laparoscopic & 2.444 & 0.609 & 11.515 & $3.491-37.979$ & $0.0001^{*}$ \\
\hline \multicolumn{6}{|l|}{ Initial procedure type } \\
\hline \multicolumn{6}{|l|}{ Total abdominal hysterectomy/oophorectomy (ref) } \\
\hline Bowel resection/upper gastrointestinal surgery/liver/pancreatic surgery & -0.177 & 0.72 & 0.838 & $0.204-3.438$ & 0.806 \\
\hline Other & 0.647 & 0.843 & 1.909 & $0.366-9.955$ & 0.443 \\
\hline
\end{tabular}

Most patients required diversion of urine via nephrostomy tube or ureteric stent, and approximately half required multiple procedures until definitive management was completed. Patients experienced prolonged admissions to hospital and re-admissions, increasing the cost to the healthcare system. In other, larger studies, delayed recognition of IUI has also been shown to have negative consequences to the patient and increased costs for the healthcare system. 3,4,16,17

Fortunately, in our series of 103 patients, we did not identify a direct relationship between delayed recognition of IUI and hydronephrosis, ureteric stricture, and ureteric obstruction after definitive treatment. This is likely because most of the patients in our study had good outcomes regardless of when the injury was recognized; only $10 \%$ had new or worsening hydronephrosis, $5 \%$ had ureteric stricture, and $4 \%$ had ureteric obstruction. In a series of 82 IUIs Al-Awadi et al also found a high success rate of repair (93.9\%) regardless of the timing of diagnosis or type of repair. ${ }^{16}$

In general, gynecological and general surgical procedures are being done more frequently with minimally invasive techniques (i.e., laparoscopic or robotic). ${ }^{18,19} \mathrm{We}$ also noted this in our series. In the first half of the study period, 5.8\% of procedures were done laparoscopically, while in the second half, $25.5 \%$ of procedures were done laparoscopically. Using the Danish National Colorectal Cancer database of 18474 patients, Andersen et al found a higher rate of IUI in surgeries conducted laparoscopically as compared to an open approach $(0.6 \%$ vs. $0.4 \%, p=0.03) .{ }^{13}$ Over time in our series, where most of the laparoscopic procedures were done in the latter half of the study period, we noted a higher proportion of the IUIs being recognized in a delayed manner (25.5\% from 2011 onwards vs. 13.5\% before 2011). Patients who underwent laparoscopic surgery had an 11 times more likely chance of having an unrecognized IUI as compared to those who underwent open surgery (OR 11.515, $\mathrm{p}=0.0001$ ). As the number of laparoscopic surgeries increases, we may see a higher incidence of IUI in the future, in particular those recognized in a delayed manner.

To prevent complications associated with unrecognized IUI, it is important to focus on intraoperative detection of IUI. Several published studies have explored methods to improve detection. The use of prophylactic ureteric stents has been reviewed in general surgery and gynecology. In a systematic review of 22 studies of general surgery cases, Croghan et al found a slightly higher incidence of IUI in prophylactically stented (1521/102 370, 1.49\%) vs. non-stented (1333/767 $233,0.17 \%$ ) patients but did not find a statistically significant difference in intraoperative recognition of IUI between prophylactically stented (10/16) and non-stented (9/17) patients $(p=0.579) .{ }^{20}$ Dumont et al examined 155 pelvic surgery cases in a tertiary referral hospital and noted that the prophylactic ureteric stent significantly enhanced intraoperative diagnosis of IUI (OR 5.09, 95\% CI 2.26-11.48); ${ }^{21}$ however, prophylactic ureteric stent placement was not associated with reduced rates of IUI, nor their complications. Thus, the benefit of prophylactic stenting to protect ureters is not clear. 
Cystoscopy to assess for lack of ureteric jet associated with IUI has also been reviewed in gynecological procedures, with conflicting results. ${ }^{22,23}$ Lack of a ureteric jet on cystoscopy would normally trigger further workup for the injury with a retrograde pyelogram. Because IUI are so rare in common gynecological procedures, Cadish et al conducted a cost analysis and found that routine cystoscopy is not cost-effective in detecting IUI; ${ }^{24}$ however, selective cystoscopy in high-risk cases, where risk of IUI exceeds $3.96-8.95 \%$, is less expensive than no cystoscopy at all after weighing cost factors of diagnostic tests, treatments, and complications.

The results from our study highlight the need to identify cases defined as high-risk. The incidence of IUI is low, approximately $0.244 \%{ }^{25}$ and $<0.5 \%$ for laparoscopic colectomy and laparoscopic hysterectomy, respectively. ${ }^{26}$ Therefore, it is unlikely that selective cystoscopy to identify ureteric jets is financially justified for detection of IUIs with such a low incidence rate.

The addition of an oral or intravenous agent to help detect ureteric jets has also been evaluated. Grimes et al conducted a randomized clinical trial $(n=130)$ that compared surgeon satisfaction in using four different ways of detecting IUI: preoperative oral phenazopyridine, intraoperative intravenous sodium fluorescein, $20 \%$ mannitol, or normal saline immediately prior to the intraoperative cystoscopy. ${ }^{27}$ Surgeons in the study rated intravenous mannitol to be the most helpful in visualizing ureteric jets. There were no differences in cystoscopy length, time to surgeon confidence in visualization of ureteric jets, and adverse events at 189 days of followup. Future studies should continue to evaluate prophylactic stenting and other methods, such as near-infrared fluorescence and experimental dyes, ${ }^{28,29}$ for immediate identification of IUI.

There are limitations to this study. The data were collected retrospectively. Based on the identification of IUI through an institutional medical records system, some injuries may have been missed. For example, a ureter that was injured by a urologist and repaired by the same urologist intraoperatively may not have been recorded as an IUI. Our cohort was relatively small, especially for those with a delayed diagnosis of IUI (21/103). Thus, our ability to characterize morbidity and identify all predictors was limited by the availability of data and our adjustment for other factors, such as comorbidities in the logistic regression analyses. Nonetheless, this is one of the largest case series to date evaluating IUI, ${ }^{8-14}$ and the only study, of which we are aware, that evaluates predictors for delayed recognition of IUI.

\section{Conclusions}

Although IUI are uncommon, they may have significant consequences to the patient and healthcare system. In this retrospective case series, we identified laparoscopic surgery as a predictor for delayed recognition of IUI. This information underscores the need for future studies to optimize intraoperative techniques to identify IUI, particularly in laparoscopic cases.

Competing interests: Dr. Herschorn has been an advisory board member for and has received payment from Astellas, Boston Scientific, and Pfizer; has received speaker honoraria from Astellas; and has participated in clinical trials supported by Astellas, Allergan, and Purdue. The remaining authors do not report any competing personal or financial interests related to this work.

This paper has been peer-reviewed.

\section{References}

1. Chung D, Briggs J, Turney BW, et al. Management of iatrogenic ureteric injury with retrograde ureteric stenting: An analysis of factors affecting technical success and long-term outcome. Acta Radiol 2017;58:170-5. https://doi.org/10.1177/0284185116638568

2. Gild $P$, Kluth $L A$, Vetterlein $M W$, et al. Adult iatrogenic ureteral injury and stricture-incidence and treatment strategies. Asian J Urol 2018;5:101-6. https://doi.org/10.1016/i.ajur.2018.02.003

3. Blackwell RH, Kirshenbaum EJ, Shah AS, et al. Complications of recognized and unrecognized iatrogenic ureteral injury at time of hysterectomy: A population-based analysis. J Urol 2018;199:1540-5. https://doi.org/10.1016/i.juro.2017.12.067

4. Hove LD, Bock J, Christoffersen JK, et al. Analysis of 136 ureteral injuries in gynecological and obstetrical surgery from completed insurance claims. Acta Obstet Gynecol Scand 2010;89:82-6. https://doi.org/10.3109/00016340903433974

5. Engel 0 , Rink $M$, Fisch $M$. Management of iatrogenic ureteral injury and techniques for ureteral reconstruction. Curr Opin Urol 2015;25:331-5. https://doi.org/10.1097/MOU.0000000000000175

6. Abboudi H, Ahmed K, Royle J, et al. Ureteric injury: A challenging condition to diagnose and manage. Nat Rev Urol 2013;10:108-15. https://doi.org/10.1038/nrurol.2012.254

7. Burks FN, Santucci RA. Management of iatrogenic ureteral injury. Ther Adv Urol 2014;6:115-24. https://doi.org/10.1177/1756287214526767

8. Tracey AT, Eun DD, Stifelman MD, et al. Robotic-assisted laparoscopic repair of ureteral injury: An evidence-based review of techniques and outcomes. Minerva Urol Nefrol 2018;70:231-41. https://doi.org/10.23736/S0393-2249.18.03137-5

9. Matsumura $Y$, lemura $Y$, Fukui $S$, et al. latrogenic injuries of urinary tract: Outcomes of surgical repairs. Hinyokika Kiyo 2018;64:95-9. https://doi.org/10.14989/actauroljap_64_3_95

10. Eswara JR, Raup VT, Potretzke AM, et al. Outcomes of iatrogenic genitourinary injuries during colorectal surgery. Urology 2015;86:1228-33. https://doi.org/10.1016/i.urology.2015.06.065

11. Selzman AA, Spirnak JP. Iatrogenic ureteral injuries: A 20-year experience in treating 165 injuries. J Urol 1996;155:878-81. https://doi.org/10.1016/S0022-5347(01)66332-8

12. Chalya PL, Massinde AN, Kihunrwa A, et al. latrogenic ureteric injuries following abdomino-pelvic operations: A 10-year tertiary care hospital experience in Tanzania. World J Emerg Surg 2015;10:17. https://doi.org/10.1186/s13017-015-0011-z

13. Andersen $P$, Andersen $L M$, Iversen LH. latrogenic ureteral injury in colorectal cancer surgery: A nationwide study comparing laparoscopic and open approaches. Surg Endosc 2015;29:1406-12. https://doi.org/10.1007/s00464-014-3814-1

14. Bašić D, Ignjatović I, Potić M. latrogenic ureteral trauma: A 16-year, single tertiary center experience. Srp Arh Celok Lek 2015;143:162-8.htrps://doi.org/10.2298/SARH1504162B

15. Morrow J, Curry D, Dooher M, et al. Minimally invasive management of delayed recognition iatrogenic ureteric injury. Ulster Med J 2017;86:181-4. http://www.ncbi.nlm.nih.gov/pmc/articles/pmc5849975/

16. Al-Awadi K, Kehinde EO, Al-Hunayan A, et al. Iatrogenic ureteric injuries: Incidence, etiological factors and the effect of early management on subsequent outcome. Int Urol Nephrol 2005;37:235-41. https://doi.org/10.1007/s1 1255-004-7970-4

17. Gilmour DT, Baskett TF. Disability and litigation from urinary tract injuries at benign gynecologic surgery in Canada. Obstet Gynecol 2005;105:109-14. https://doi.org/10.1097/01. AOG.0000144127.78481.8c 
Locke et al

18. Tsui C, Klein R, Garabrant M. Minimally invasive surgery: National trends in adoption and future directions for hospital strategy. Surg Endosc 2013;27:2253-7. https://doi.org/10.1007/s00464-013-2973-9

19. Twijnstra AR, Kolkman W, Trimbos-Kemper GC, et al. Implementation of advanced laparoscopic surgery in gynecology: National overview of trends. J Minim Invasive Gynecol 2010;17:487-92. https://doi.org/10.1016/i.jmig.2010.03.010

20. Croghan SM, Zaborowski A, Mohan HM, et al. The sentinel stent? A systematic review of the role of prophylactic ureteric stenting prior to colorectal resections. Int J Colorectal Dis 2019;34:1161-78. https://doi.org/10.1007/s00384-019-03314-1

21. Dumont $S$, Chys B, Meuleman C, et al. Prophylactic ureteral catheterization in the intraoperative diagnosis of iatrogenic ureteral injury. Acta Chir Belg 2021;121:261-6. https://doi.org/10.1080/00015458 .2020 .1753148

22. Peacock $L M$, Young A, Rogers RG. Universal cystoscopy at the time of benign hysterectomy: A debate. Am J Obstet Gynecol 2018;219:75-7. https://doi.org/10.1016/i.ajog.2018.04.020

23. Findley AD, Solnik MJ. Prevention and management of urologic injury during gynecologic laparoscopy. Curr Opin Obstet Gynecol 2016;28:323-8. hitps://doi.org/10.1097/GC0.0000000000000296

24. Cadish LA, Ridgeway BM, Shepherd JP. Cystoscopy at the time of benign hysterectomy: A decision analysis. Am J Obstet Gynecol 2019;220:369.el-7. https://doi.org/10.1016/..ajog.2019.01.217
25. Palaniappa NC, Telem DA, Ranasinghe NE, et al. Incidence of iatrogenic ureteral injury after laparoscopic colectomy. Arch Surg 2012;147:267-71. https://doi.org/10.1001/archsurg.2011.2029

26. Kiran A, Hilton P, Cromwell DA. The risk of ureteric injury associated with hysterectomy: A 10-year retrospective cohort study. BJOG 2016;123:1184-91. https://doi.org/10.1111/1471-0528.13576

27. Grimes CL, Patankar S, Ryntz T, et al. Evaluating ureteral patency in the post-indigo carmine era: A randomized controlled trial. Am J Obstet Gynecol 2017;217:601.el-10. htrps://doi.org/10.1016/i. ajog.2017.07.012

28. Douissard J, Ris F, Morel P, et al. Current strategies to prevent iatrogenic ureteral injury during colorectal surgery. Surg Technol Int 2018:32:119-24.

29. Slooter MD, Janssen A, Bemelman WA, et al. Currently available and experimental dyes for intraoperative near-infrared fluorescence imaging of the ureters: A systematic review. Tech Coloproctol 2019;23:305-13. https://doi.org/10.1007/s10151-019-01973-4

Correspondence: Dr. Sender Herschorn, University of Toronto, Sunnybrook Health Sciences Centre, Toronto, 0N, Canada; s.herschorn@utoronto.ca 